JPE 11-3-3

\title{
Novel Passive Snubber Suitable for Three-Phase Single-Stage PFC Based on an Isolated Full-Bridge Boost Topology
}

\author{
Tao Meng ${ }^{\dagger}$, Hongqi Ben*, Daqing Wang*, and Jianfeng Song* \\ $\dagger^{*}$ School of Electrical Engineering and Automation, Harbin Institute of Technology, Harbin, China
}

\begin{abstract}
In this paper a novel passive snubber is proposed, which can suppress the voltage spike across the bridge leg of the isolated full-bridge boost topology. The snubber is composed of capacitors, inductors and diodes. Two capacitors connected in series are used to absorb the voltage spike and the energy of each capacitor can be transferred to the load during one switching cycle by the resonance of the inductors and capacitors. The operational principle of the passive snubber is analyzed in detail based on a three-phase power factor correction (PFC) converter, and the design considerations of both the converter and the snubber are given. Finally, a $3 \mathrm{~kW}$ laboratory-made prototype is built. The experimental results verify the theoretical analysis and evaluations. They also prove the validity and feasibility of the proposed methods.
\end{abstract}

Key Words: Isolated full-bridge boost topology, Passive, Snubber, Three-phase power factor correction (PFC), Voltage spike

\section{INTRODUCTION}

Power factor correction (PFC) is one of the most effective methods for reducing harmonic current and increasing power factor [1]-[4]. Based on their circuit structures, PFC techniques are usually divided into two categories: two-stage and single-stage approaches. The first stage of the two-stage approach is a PFC circuit and the second stage is a DC/DC converter. As a result of these two processing stages, conversion efficiency is reduced and an extra PFC stage adds both components and complexity. The single-stage approach can overcome these drawbacks. This approach uses only one stage circuit to achieve both PFC and DC/DC conversion, and it has the advantages such as high efficiency, simplicity and low cost [5]-[8]. Therefore, single-stage PFC is an important developing orientation of PFC techniques [9], [10].

The isolated full-bridge boost topology is attractive in applications such as isolated DC/DC converters, as well as single-phase and three-phase single-stage PFC. This is due to the fact that it can: 1) realize electrical isolation between the input and output sides and the output voltage regulation, 2) achieve soft-switching for all of the switches, and 3) avoid the short-through problem of bridge leg switches [11]-[14]. However, the topology itself has a serious problem. Due to the existence of the transformer leakage inductance, there is

\footnotetext{
Manuscript received Oct. 12, 2010; revised Mar. 10, 2011

Recommended for publication by Associate Editor Yong-Chae Jung.

$\dagger$ Corresponding Author: mengtao@hit.edu.cn

Tel: +86-451-86413602, Fax: +86-451-86413602, Harbin Institute of Tech.

${ }^{*}$ School of Electrical Engineering and Automation, Harbin Institute of Technology, China
}

a voltage spike across the bridge leg, which will increase the voltage stress on each of the switches and decrease the reliability of the topology [15], [16].

To suppress the voltage spike, a number of techniques have been proposed. A method based on the active clamping technique is introduced in [17]-[20], a passive clamping technique is proposed in [21] and a passive snubber is investigated in [22], [23]. The voltage spike is efficiently suppressed after the adoption of each of the above methods. However, all of them have their own drawbacks. 1) For the first method, an additional switch is introduced, which increases the complexity of control circuit and reduces the reliability of the whole system, moreover, the switching frequency of the additional switch is two times as high as that of the main switches, so it is difficult to choose the additional switch. 2) For the second method, the problem of magnetic bias of the power transformer appears after the adoption of the passive clamping circuit. 3) For the third method, a diode is connected in series with the bridge leg switches, which increases some of the losses and reduces the efficiency of the converter.

In this paper, a novel passive snubber is proposed, and its investigation is based on a three-phase single-stage PFC converter. Theoretical analysis and experimental results show that the voltage spike can be suppressed efficiently after the adoption of the snubber which can also overcome the drawbacks of the methods in [17]-[23].

\section{Operational PRINCIPLE}

A three-phase single-stage PFC converter based on an isolated full-bridge boost topology is shown in Fig. 1, where 


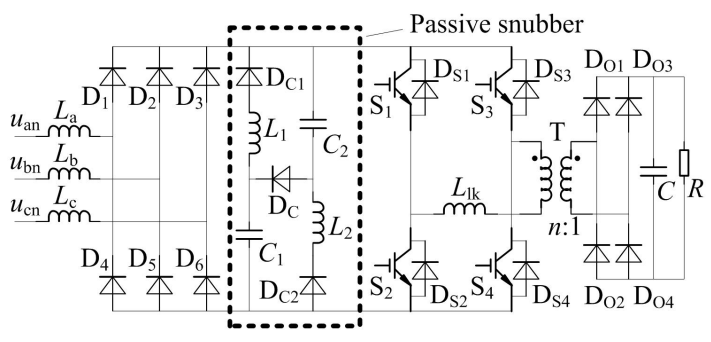

Fig. 1. Three-phase single-stage PFC converter based on isolated full-bridge boost topology.

the passive snubber proposed in this paper is composed of $C_{1}, C_{2}\left(C_{1}=C_{2}\right), L_{1}, L_{2}\left(L_{1}=L_{2}\right), D_{C 1}, D_{C 2}$ and $D_{C}$. The PFC converter is mainly made up of six parts: a threephase input $\mathrm{AC}$ source $u_{a n}, u_{b n}$ and $u_{c n}$, an input rectifier, a passive snubber, a phase shift full bridge (PSFB), a high frequency transformer, an output rectifier and a filter. $L_{a}, L_{b}$, $L_{c}\left(L_{a}=L_{b}=L_{c}=L\right)$ are the boost inductors. The PSFB is the main part of the converter, where the duty cycle of each switch is fixed at $50 \%$, the switching states of $S_{1} \& S_{2}$ are contrary to those of $S_{3} \& S_{4}$ and the switching phase between $S_{1}$ and $S_{2}, S_{3}$ and $S_{4}$ can be controlled to regulate the output voltage. $D_{S 1}-D_{S 4}$ are the body diodes of the switches $\mathrm{S}_{1}-\mathrm{S}_{4}$, $L_{l k}$ and $n$ are the equivalent leakage inductance and the voltage ratio of transformer $\mathrm{T}$, respectively.

The converter in Fig. 1 operates in discontinuous current mode (DCM). When the bridge leg switches are shorted $\left(\mathrm{S}_{1}\right.$ $\& S_{2}$ or $S_{3} \& S_{4}$ are turning on), the boost inductors are charged by $u_{a n}, u_{b n}$ and $u_{c n}$, and the input current increases almost linearly. When the bridge diagonal-leg switches turn on $\left(S_{1} \& S_{4}\right.$ or $S_{2} \& S_{3}$ are turning on), the output current is provided by $u_{a n}, u_{b n}$ and $u_{c n}$ and $L_{a}, L_{b}$ and $L_{c}$, and the input current decreases. It can be seen that the process above is repeated periodically. The discontinuous input current follows the envelopes which are proportional to the input voltage. Therefore, both PFC and AC/DC conversion can be achieved.

To simplify the analysis, we assumed that: 1) all devices are ideal, 2) the capacitor $C$ is large enough, so the output voltage $U_{o}$ can be considered as a constant value, and 3) during one switching period, the changes in $u_{a n}, u_{b n}$ and $u_{c n}$ are negligible because the switching period is much shorter than the line period. The following analysis is during one charging period of the boost inductors in the time phase of $0 \leq \omega t \leq \pi / 6$, in which the relation of the three-phase voltage is $u_{b n} \leq 0 \leq u_{a n} \leq$ $u_{c n}$. The theoretical waveforms and the equivalent circuits of different stages are shown in Fig.2 and Fig.3, respectively.

Stage 1 (before $t_{0}$ ): $S_{2}$ and $S_{3}$ are turning on, while $S_{1}$ and $\mathrm{S}_{4}$ are turning off. The converter operates in DCM, so the current of the boost inductors has been reduced to zero before $t_{0}$, and then the current in both the primary and secondary sides of transformer $\mathrm{T}$ is zero. The voltage across the primary side of transformer T: $U_{k}=n U_{o}, U_{C 1}=U_{C 2}=n U_{o} / 2, U_{S 1}=U_{S 4}=n U_{o}$ and $U_{S 2}=U_{S 3}=0$. The diodes $\mathrm{D}_{\mathrm{S} 1}-\mathrm{D}_{\mathrm{S} 4}$ are all turning off. In this stage, the output current is only provided by capacitor $C$.

Stage $2\left(t_{0}-t_{1}\right)$ : At $t_{0}, S_{1}$ turns on with a zero current, and $S_{3}$ turns off with a zero voltage and current. The diodes $\mathrm{D}_{1}, \mathrm{D}_{3}$ and $\mathrm{D}_{5}$ are turned on, and the current of the boost inductors $i_{L a}, i_{L b}$ and $i_{L c}$ increases linearly. In the snubber circuit, $C_{1}$

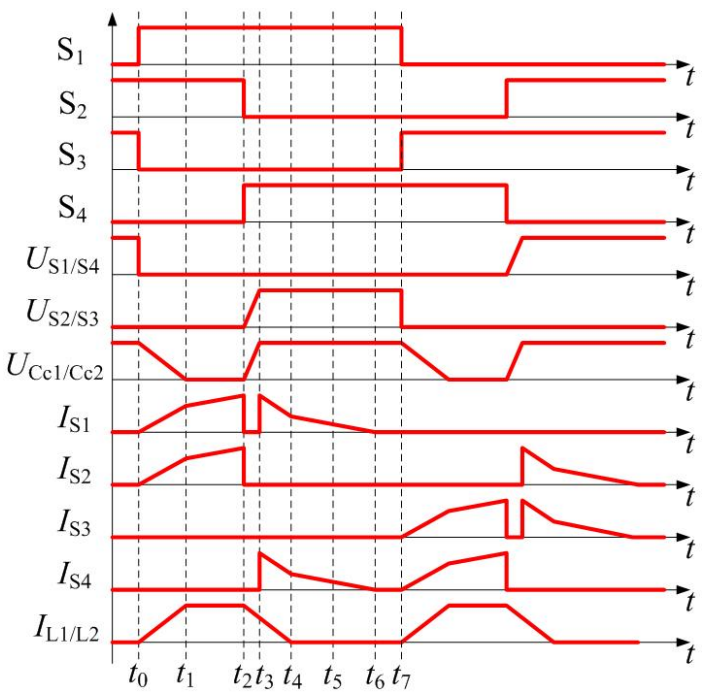

Fig. 2. Theoretical waveforms.

is resonant with $L_{1}$ through $\mathrm{D}_{\mathrm{C} 1}, \mathrm{~S}_{1}$ and $\mathrm{S}_{2}$. Furthermore, $C_{2}$ is resonant with $L_{2}$ through $\mathrm{S}_{1}, \mathrm{~S}_{2}$ and $\mathrm{D}_{\mathrm{C} 2}$. Therefore, the voltage of $C_{1} \& C_{2}$ and the current in $L_{1} \& L_{2}$ are:

$$
\begin{gathered}
u_{\mathrm{C} 1 / \mathrm{C} 2}(t)=\frac{1}{2} n U_{\mathrm{o}} \cos \frac{1}{\sqrt{L_{1} C_{1}}}\left(t-t_{0}\right) \\
i_{\mathrm{L} 1 / \mathrm{L} 2}(t)=\frac{n U_{\mathrm{o}}}{2} \sqrt{\frac{C_{1}}{L_{1}}} \sin \frac{1}{\sqrt{L_{1} C_{1}}}\left(t-t_{0}\right) .
\end{gathered}
$$

At $t_{1}, U_{C 1}=U_{C 2}=0$, and the energy of $C_{1}$ and $C_{2}$ is transferred to $L_{1}$ and $L_{2}$ entirely. In this stage, the output current is only provided by capacitor $C$. The duration of this stage is calculated as:

$$
t_{01}=\frac{\pi}{2} \sqrt{L_{1} C_{1}} .
$$

Stage $3\left(t_{1}-t_{2}\right)$ : In this stage, $i_{L a}, i_{L b}$ and $i_{L c}$ still increase linearly, and the output current is also provided by capacitor $C$ alone. The voltage of $C_{1}$ or $C_{2}$ is zero, so diode $\mathrm{D}_{\mathrm{C}}$ is turned on, $L_{1}$ is connected in series with $L_{2}$, and their current flows through $\mathrm{D}_{\mathrm{C} 1}, \mathrm{~S}_{1}, \mathrm{~S}_{2}, \mathrm{D}_{\mathrm{C} 2}$ and $\mathrm{D}_{\mathrm{C}}$.

Stage $4\left(t_{2}-t_{3}\right)$ : At $t_{2}, \mathrm{~S}_{2}$ turns off, and $\mathrm{S}_{4}$ turns on with a zero voltage. $C_{1}$ and $C_{2}$ are charged by $L_{a}, L_{b}, L_{c}, L_{1}$ and $L_{2}$. The voltage across the bridge leg increases from zero, so $S_{2}$ turns off with a zero voltage. The inductance of each boost inductor is large enough, so that the change in their current can be ignored during this small charging period. The voltage expression of $C_{1}$ or $C_{2}$ is given in (4):

$$
\begin{gathered}
u_{\mathrm{C} 1 / \mathrm{C} 2}(t)=\frac{I_{\mathrm{L} 1 / \mathrm{L} 2 \text { peak }}-I_{\text {Lbpeak }}}{C_{1}}\left(t-t_{2}\right) \\
I_{\mathrm{L} 1 / \mathrm{L} 2 \text { peak }}=\frac{n U_{\mathrm{o}}}{2} \sqrt{\frac{C_{1}}{L_{1}}} \\
I_{\text {Lbpeak }}=\frac{u_{\mathrm{bn}}}{L} D T
\end{gathered}
$$

where, $T$ is the charging period of the boost inductors, and $D=\left(t_{2}-t_{0}\right) / T$ is the duty cycle of the converter.

At $t_{3}$, the charging process of $C_{1}$ and $C_{2}$ is over. Therefore, $U_{k}=-n U_{o}, U_{C 1}=U_{C 2}=n U_{o} / 2, U_{S 1}=U_{S 4}=0$ and $U_{S 2}=$ 


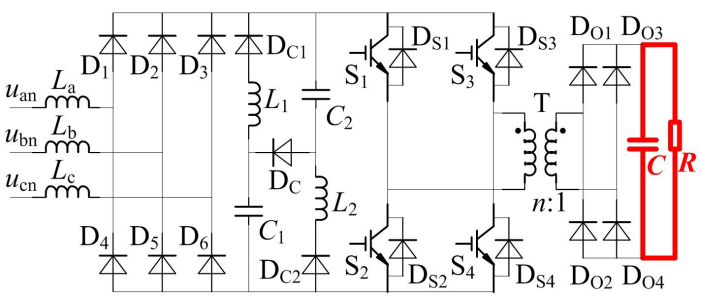

(a) Stage 1 and stage 8 .

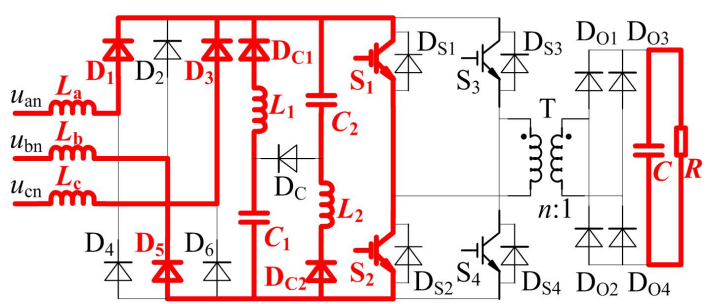

(b) Stage 2 .

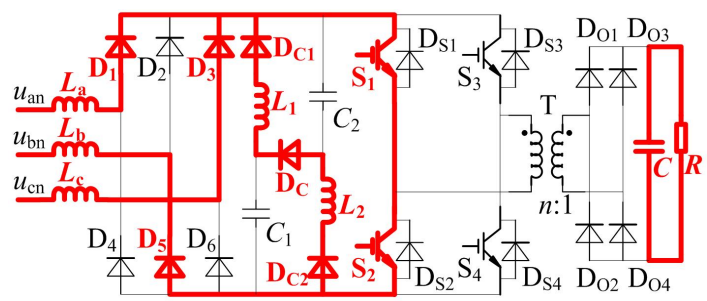

(c) Stage 3 .

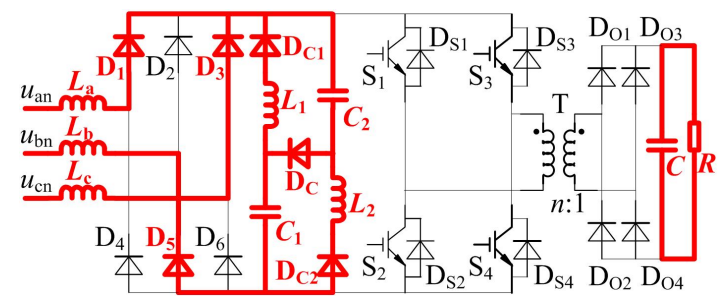

(d) Stage 4 .

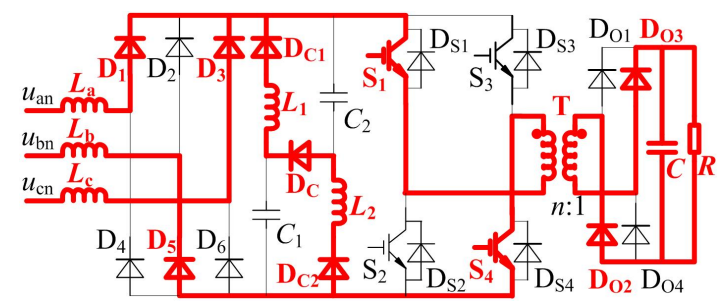

(e) Stage 5 .

$U_{S 3}=n U_{o}$. In this stage, the output current is only provided by capacitor $C$. The duration of this stage is calculated as:

$$
t_{23}=\frac{n U_{\mathrm{o}} C_{1}}{2\left(I_{\mathrm{L} 1 / \mathrm{L} 2 \text { peak }}-I_{\text {Lbpeak }}\right)} .
$$

Stage $5\left(t_{3}-t_{4}\right)$ : In this stage, the current of $L_{a}, L_{b}, L_{c}, L_{1}$ and $L_{2}$ flows through $\mathrm{S}_{1}, \mathrm{~S}_{4}$ and transformer $\mathrm{T}$ to the load, and then it begins to decrease. On the secondary side of transformer $\mathrm{T}$, $\mathrm{D}_{\mathrm{O} 2}$ and $\mathrm{D}_{\mathrm{O} 3}$ turn on. In this stage, the expression of $i_{L 1}$ and $i_{L 2}$ is:

$$
i_{\mathrm{L} 1 / \mathrm{L} 2}(t)=I_{\mathrm{L} 1 / \mathrm{L} 2 \text { peak }}-\frac{n U_{\mathrm{o}}}{2 L_{1}}\left(t-t_{3}\right) .
$$

At $t_{4}, i_{L 1}$ and $i_{L 2}$ reduce to zero, so that the duration of this

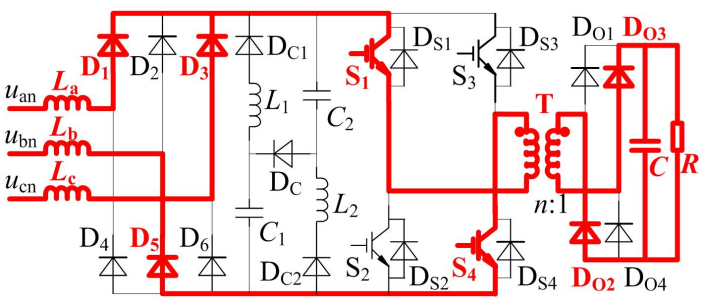

(f) Stage 6.

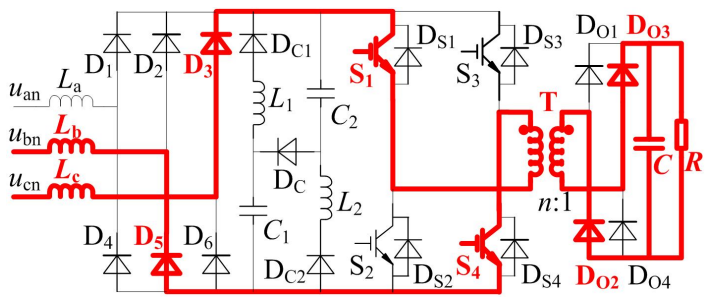

(g) Stage 7.

Fig. 3. Equivalent circuit of each stage.

stage is calculated as:

$$
t_{34}=\sqrt{L_{1} C_{1}} .
$$

Stage $6\left(t_{4}-t_{5}\right)$ : In this stage, $i_{L a}, i_{L b}$ and $i_{L c}$ still decrease. At $t_{5}, i_{L a}$ reduces to zero, and $\mathrm{D}_{1}$ turns off.

Stage $7\left(t_{5}-t_{6}\right)$ : In this stage, $i_{L b}$ and $i_{L c}$ still decrease. At $t_{6}, i_{L b}$ and $i_{L c}$ reduces to zero, and $\mathrm{D}_{3}, \mathrm{D}_{5}, \mathrm{D}_{\mathrm{O} 2}$ and $\mathrm{D}_{\mathrm{O} 3}$ turn off.

Stage $8\left(t_{6}-t_{7}\right)$ : The equivalent circuit of this stage is the same as that of stage 1 . The current on the primary side of the transformer is zero and the output current is only provided by capacitor $C$.

In the analysis above, it is assumed that $u_{a n}$ is large enough that $i_{L a}$ reduces to zero after $i_{L 1}$ (or $i_{L 2}$ ). If $u_{a n}$ is not large enough, $i_{L a}$ will reduce to zero before $i_{L 1}$ (or $i_{L 2}$ ). After $t_{7}$, the converter operates in another charging period of the boost inductors, and the switching states between $S_{1} \& S_{3}$ and between $S_{2} \& S_{4}$ are exchanged.

\section{DESIGN CONSIDERATIONS}

\section{A. Voltage stress of switches $S_{1} \sim S_{4}$}

From the analysis above, it can be seen that when the bridge diagonal-leg switches turn on, the voltage across the bridge is equal to that across the primary side of the transformer $\left(U_{k}\right)$. It is known that under ideal conditions $U_{k}=n U_{o}$. However, under real conditions, the voltage inducted by the leakage inductance of the transformer $\left(L_{l k}\right)$ must be considered.

At $t_{2}$, the bridge diagonal-leg switches turn on. At this moment, the current of the boost inductors increases to the maximum value of one charging cycle, and the boost inductors begins to discharge though the load. The equivalent circuit at this moment is shown in Fig. 4, where $C_{C}=C_{1} / 2$.

At $t_{2}, U_{C c}=0, i_{L l k}=0, i_{C c}=-i_{L b}$, and the voltage of $C_{C}$ begins to increase. The time $t_{S}$ is defined here. At $t_{S}$, the voltage of $C_{C}$ is increased to $n U_{o}$, that is $U_{C c}\left(t_{S}\right)=n U_{o}$. As a result, after $t_{S}, i_{L l k}$ increases, $i_{C c}$ decreases, and the voltage of $C_{C}$ continues to increase. The decrease in current $-i_{L b}$ can 


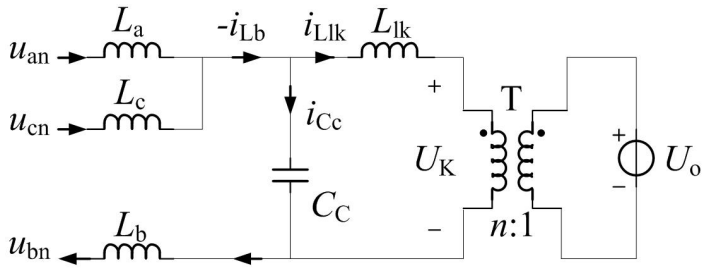

Fig. 4. Equivalent circuit.

be ignored at this point. Therefore, after $t_{S}$ the following is obtained:

$$
\begin{gathered}
i_{\mathrm{Cc}}\left(t-t_{\mathrm{S}}\right)+i_{\mathrm{Llk}}\left(t-t_{\mathrm{S}}\right)=-i_{\mathrm{Lb}} \\
i_{\mathrm{Cc}}\left(t-t_{\mathrm{S}}\right)=C_{\mathrm{C}} \frac{\mathrm{d} \Delta u_{\mathrm{Cc}}\left(t-t_{\mathrm{S}}\right)}{\mathrm{d} t} \\
\Delta u_{\mathrm{Cc}}\left(t-t_{\mathrm{S}}\right)=L_{\mathrm{lk}} \frac{\mathrm{d} i_{\mathrm{Llk}}\left(t-t_{\mathrm{S}}\right)}{\mathrm{d} t}
\end{gathered}
$$

where, $\Delta u_{\mathrm{Cc}}\left(t-t_{\mathrm{S}}\right)$ is the increasing value of the voltage of $C_{C}$ after $t_{S}$.

From (10), (11) and (12), the following differential equation is obtained:

$$
\Delta u_{\mathrm{Cc}}\left(t-t_{\mathrm{S}}\right)+L_{\mathrm{lk}} C_{\mathrm{C}} \frac{\mathrm{d}^{2} \Delta u_{\mathrm{Cc}}\left(t-t_{\mathrm{S}}\right)}{\mathrm{d} t^{2}}=0 .
$$

This equation (13) has the following initial data:

$$
\begin{gathered}
\Delta u_{\mathrm{Cc}}\left(t_{\mathrm{S}}\right)=0 \\
i_{\mathrm{Cc}}\left(t_{\mathrm{S}}\right)=-i_{\mathrm{Lb}} \\
i_{\mathrm{Llk}}\left(t_{\mathrm{S}}\right)=0 .
\end{gathered}
$$

As a result, the solution of (13) is:

$$
\Delta u_{\mathrm{Cc}}\left(t-t_{\mathrm{S}}\right)=-i_{\mathrm{Lb}} \sqrt{\frac{2 L_{\mathrm{lk}}}{C_{1}}} \sin \frac{\sqrt{2} t}{\sqrt{L_{\mathrm{lk}} C_{1}}}
$$

Therefore, the voltage of the four switches can be obtained as follows:

$$
U_{\mathrm{S}}=n U_{\mathrm{o}}-i_{\mathrm{Lb}}(t) \sqrt{\frac{2 L_{\mathrm{lk}}}{C_{1}}} \sin \frac{\sqrt{2} t}{\sqrt{L_{\mathrm{lk}} C_{1}}} .
$$

\section{B. Design issue of the passive snubber}

From (18), the relationship between $U_{S}$ and $C_{1}$ can be obtained as in Fig. 5. It can be see that $U_{S}$ will decrease as $C_{1}$ increases. If the voltage spike (the latter item of (18)) is limited to within $20 \% n U_{o}$, then $C_{1}$ must be larger than $C_{11}, C_{12}$ and $C_{13}\left(C_{11}<C_{12}<C_{13}\right)$ for different leakage inductances $L_{l k 1}$, $L_{l k 2}$ and $L_{l k 3}\left(L_{l k 1}<L_{l k 2}<L_{l k 3}\right)$.

When the bridge diagonal-leg switches turn on, the voltage of $C_{1}$ (or $C_{2}$ ) is $U_{S} / 2$ (the voltage inducted by the leakage inductance is considered here). If the voltage spike is limited within $20 \% n U_{o}$, the following is obtained:

$$
U_{\mathrm{S}} / 2 \leq 0.6 n U_{\mathrm{o}} .
$$

From (19), it is known that during the phase when the bridge diagonal-leg switches turn on, the voltage of $C_{1}$ (or $C_{2}$ ) is lower than $n U_{o}$. When the bridge leg switches are shorted, the voltage of $C_{1}$ and $C_{2}$ begins to decrease. The operational

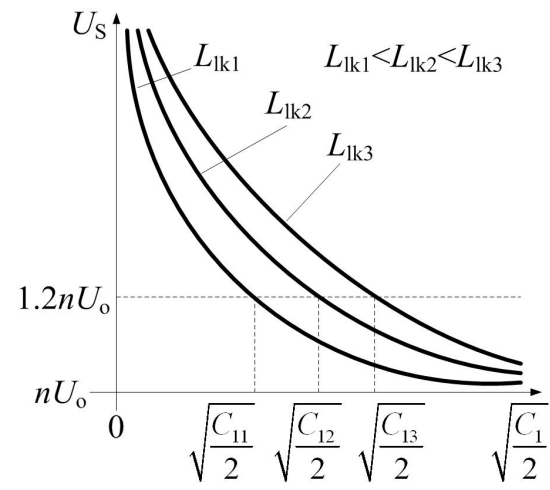

Fig. 5. Relationship between $U_{S}$ and $C_{1}$.

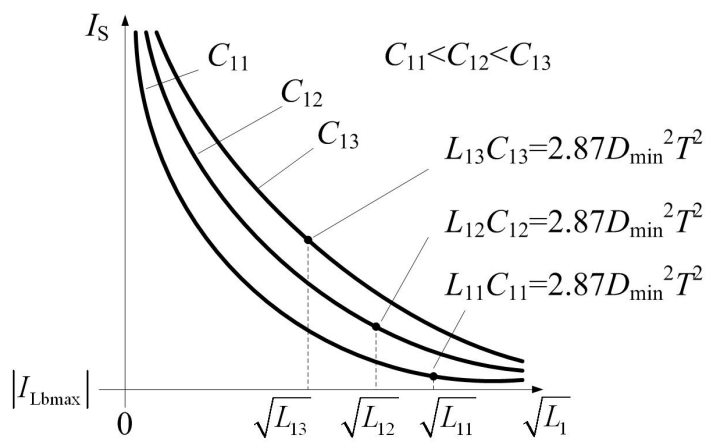

Fig. 6. Relationship between $I_{S}$ and $L_{1}$.

analysis above is under the condition where the converter is operating with a full load. As a result, the voltages of $C_{1}$ and $C_{2}$ reach to zero at the end of the phase when the bridge leg switches are shorted. On the other hand, if the converter was operating with a light load (under the minimum duty cycle $D_{\min }$ ), the voltages of $C_{1}$ and $C_{2}$ can not reach to zero during that phase. To avoid over-voltage on the bridge leg after several charging periods, the voltages of $C_{1}$ and $C_{2}$ must be lower than $n U_{o} / 2$ at the end of the phase when the bridge leg switches are shorted. As a result the following is obtained:

$$
\sqrt{L_{1} C_{1}} \arccos \frac{5}{6} \leq D_{\min } T .
$$

It is equal to:

$$
L_{1} C_{1} \leq 2.87 D_{\min }^{2} T^{2} .
$$

From the above analysis, the current stresses of the four switches can be obtained:

$$
I_{\mathrm{S}}=\left|I_{\text {Lbmax }}\right|+2 I_{\mathrm{L} 1 / \mathrm{L} 2 \text { peak }}=\left|I_{\text {Lbmax }}\right|+n U_{\mathrm{o}} \sqrt{\frac{C_{1}}{L_{1}}} .
$$

From (22), the relationship between $I_{S}$ and $L_{1}$ can be obtained in as in Fig. 6. It can be seen that $I_{S}$ increases as $C_{1}$ increases, and that it will decrease as $L_{1}$ increases. It can also be seen that to meet (20), $L_{1}$ must be lower than $L_{11}, L_{12}$ and $L_{13}\left(L_{11}>L_{12}>L_{13}\right)$ for the different capacitances $C_{11}$, $C_{12}$ and $C_{13}\left(C_{11}<C_{12}<C_{13}\right)$.

\section{EXPERIMENTAL RESULTS}

To verify the theoretical analysis and evaluations mentioned earlier, a $3 \mathrm{~kW}$ laboratory-made prototype of this converter was built. The basic circuit parameters and the main components 


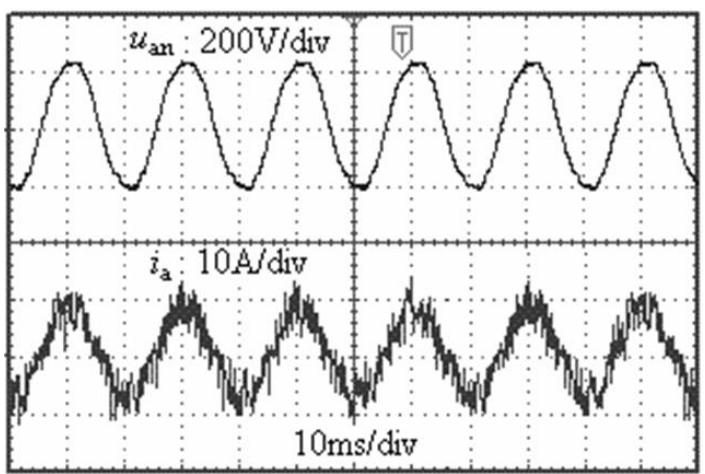

Fig. 7. Input voltage and current of phase A.

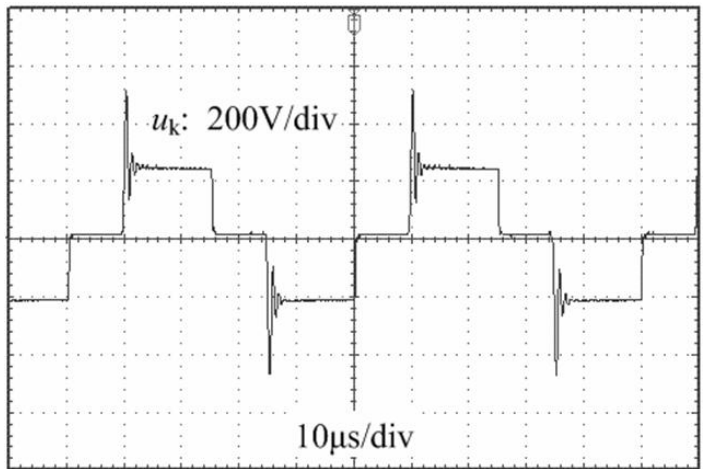

Fig. 8. Voltage across primary side of $\mathrm{T}$ without the snubber.

used in this prototype are: $L_{a}=L_{b}=L_{c}=76 \mu \mathrm{H}, L_{1}=L_{2}=$ $150 \mu \mathrm{H}, L_{l k}=6 \mu \mathrm{H}, C_{1}=C_{2}=100 \mathrm{nF}, C=1000 \mu \mathrm{F}, n=2$, $\mathrm{S}_{1}-\mathrm{S}_{4}$ : EUPEC BSM75GB120DN2 (the switching frequency is $20 \mathrm{kHz}$ ).

Fig. 7 shows the input waveforms of phase A, and the current waveform is when a simple LC low-pass filter is introduced. We can see that the input current is sinusoidal and follows the input voltage.

Fig. 8 and Fig. 9 are the voltage waveforms across the primary side of $\mathrm{T}$. To protect the circuit, the experimental result in Fig. 8 is obtained at a very low voltage, and the voltage spike is much smaller than that produced at full load $(3 \mathrm{~kW})$. The result in Fig. 9 is obtained at full load. We can see that the voltage spike is suppressed greatly after the passive snubber is adopted.

Fig. 10 to 12 show the experimental waveforms of the switches $S_{1}$ and $S_{2}$ at full load. It can be seen that $S_{1}$ achieves ZCS and turns off with a zero voltage, and $S_{2}$ achieves ZVS (the switching states of $S_{3}$ and $S_{4}$ are the same as those of $S_{1}$ and $S_{2}$, so the related results are not presented here). Fig. 13 gives the voltage waveforms of $C_{1}$, which show the charging and discharging processes of $C_{1}$.

The experimental efficiency curve is drawn in Fig. 14. As can be seen the prototype converter shows good performance in conversion efficiency, especially under full load $(3 \mathrm{~kW})$. Compared with other methods it can bee seen that: 1) the efficiency of this snubber is higher than that of a traditional RCD snubber and the passive snubbers in [22], [23], 2) the efficiency of this snubber is similar to that of the active clamping circuits in [17]-[20] and the passive clamping circuit in [21], while the reliability is much higher.

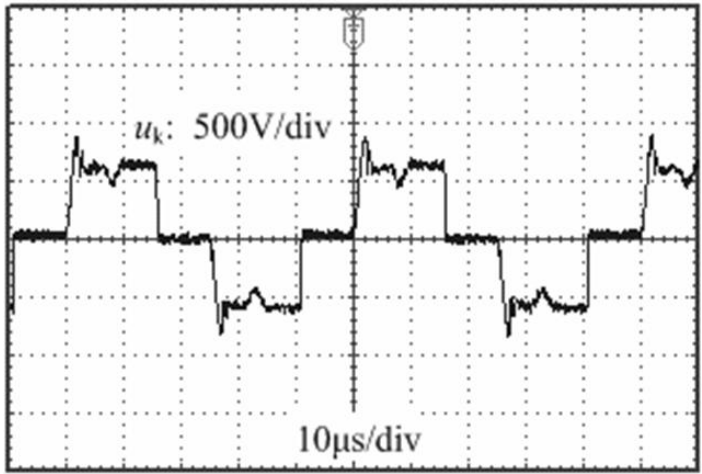

Fig. 9. Voltage across primary side of $\mathrm{T}$ with the snubber.

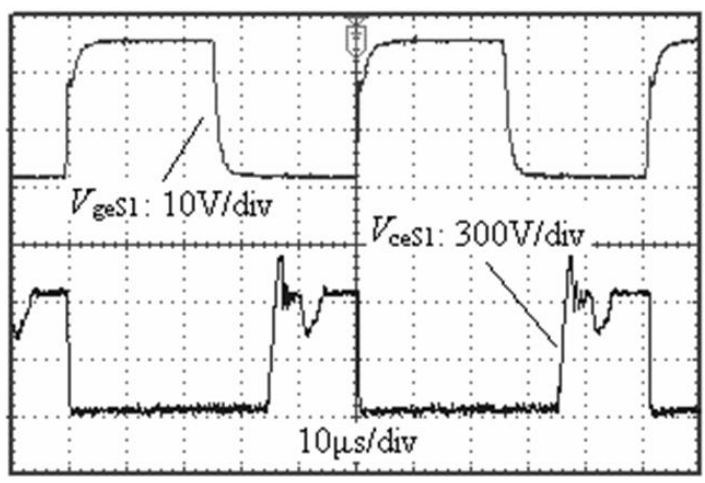

Fig. 10. Driving signal and voltage of $S_{1}$.

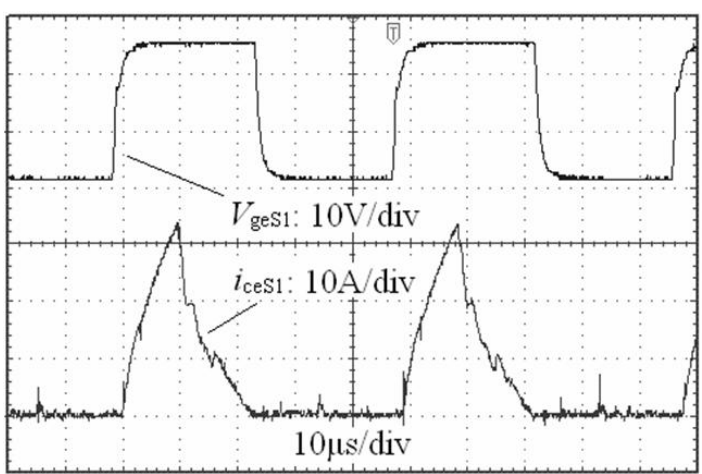

Fig. 11. Driving signal and current of $S_{1}$.

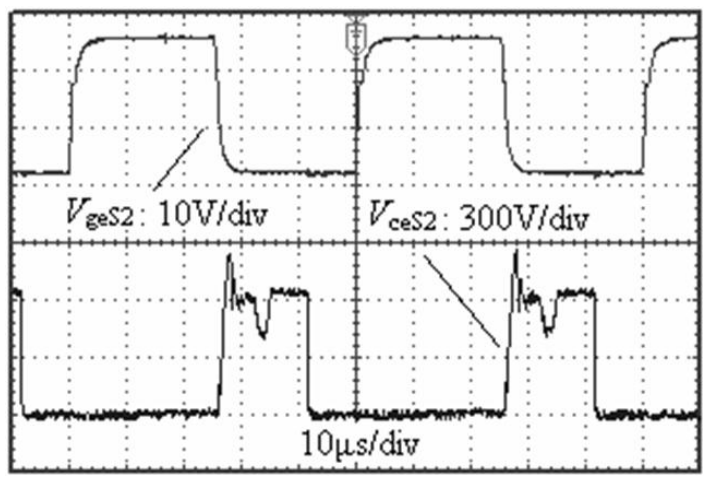

Fig. 12. Driving signal and voltage of $S_{2}$. 


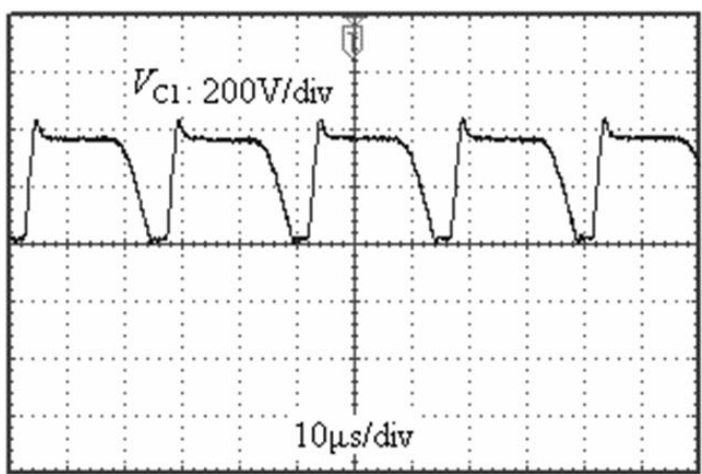

Fig. 13. Voltage of $C_{1}$.

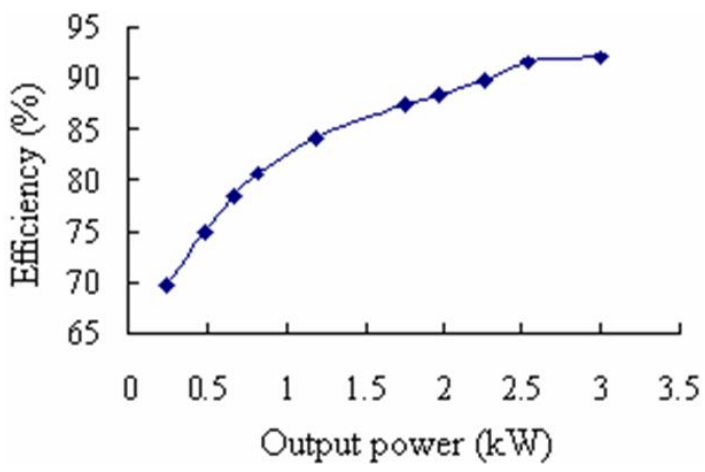

Fig. 14. Efficiency of the prototype.

\section{Conclusions}

In this paper, a novel passive snubber is proposed and investigated based on a three-phase single-stage isolated fullbridge boost PFC converter. The results show that the adoption of this snubber can realize both the suppression of the voltage spike across bridge leg switches and the energy transfer from the snubber itself to the output side. The operational principles and the design considerations of the passive snubber are discussed in detail. Finally, following the design procedure, a $3 \mathrm{~kW}$ laboratory-made prototype is built, through which the theoretical analysis and evaluations are verified.

\section{ACKNOWLEDGMENT}

This paper and its related research were supported by grants from the Power Electronics Science and Education Development Program of the Delta Environmental \& Educational Foundation.

\section{REFERENCES}

[1] G. G. Park, K. Y. Kwon and T. W. Kim, "PFC dual boost converter based on input voltage estimation for DC inverter air conditioner," Journal of Power Electronics, Vol. 10, No. 3, pp. 293-299, May 2010.

[2] A. Andre-Badin and I. Barbi, "Unity power factor isolated three-phase rectifier with split dc-bus based on the scott transformer," IEEE Trans. Power Electron., Vol. 23, No. 3, pp. 1278-1287, May 2008.

[3] S. W. Choi and Y. S. Bae, "A new unity power factor rectifier system using and active waveshaping technique," Journal of Power Electronics, Vol. 9, No. 2, pp. 173-179, Mar. 2009.

[4] K. Nishimura, K. Hirachi, E. Hiraki, N. A. Ahmed, H. W. Lee and M. Nakaoka, "Advanced three-phase PFC power converters with threephase diode rectifier and four-switch boost chopper," Journal of Power Electronics, Vol. 6, No. 4, pp.356-365, Oct. 2006.

[5] M. A. Al-Saffar, E. H. Ismail, and A. J. Sabzali, "Integrated buck-boostquadratic Buck PFC rectifier for universal input applications," IEEE Trans. Power Electron., Vol. 24, No. 12, pp. 2886-2896, Dec. 2009.
[6] M. Jabbari and H. Farzanehfard, "A new soft switching step-down/up converter with inherent PFC performance," Journal of Power Electronics, Vol. 9, No. 6, pp.835-844, Nov. 2009.

[7] G. K. Andersen and F. Blaabjerg, "Current programmed control of a single-phase two-switch buck-boost power factor correction circuit," IEEE Trans. Ind. Electron., Vol. 53, No. 1, pp. 263-271, Feb. 2006.

[8] B. H. Lee, C. E. Kim, K. B. Park, and G. W. Moon, "A new singlestage PFC AC/DC converter with low link-capacitor voltage," Journal of Power Electronics, Vol. 7, No. 4, pp. 328-335, Oct. 2007.

[9] J. M. Alonso, M. A. D. Costa, and C. Ordiz, "Integrated buck-flyback converter as a high-power-factor off-line power supply," IEEE Trans. Ind. Electron., Vol. 55, No. 3, pp. 1090-1100, Mar. 2008.

[10] J. J. Lee, J. M. Kwon, E. H. Kim, W. Y. Choi, and B. H. Kwon, "Singlestage single-switch PFC flyback converter using a synchronous rectifier," IEEE Trans. Ind. Electron., Vol. 55, No. 3, pp. 1352-1365, Mar. 2008.

[11] P. M. Barbosa and I. Barbi, "Single-switch flyback current fed dc-dc converter," IEEE Trans. Power Electron., Vol. 13, No. 3, pp. 466-475, May 1998.

[12] J. F. Chen, R. Y. Chen and T. J. Liang, "Study and implementation of a single-stage current-fed boost PFC converter with ZCS for high voltage applications," IEEE Trans. Power Electron., Vol. 23, No. 1, pp. 379-386, Jan. 2008.

[13] J. J. Albrecht, J. Young, and W. A. Peterson, "Boost-buck push-pull converter for very wide input range single stage power conversion," in Proc. IEEE APEC, pp. 303-308, 1995.

[14] T. Meng, H. Q. Ben, and G. S. Shi, "Research on a novel three-phase single-stage soft-switching PFC converter," in Proc. IEEE ICIEA, pp. 246-249, 2008.

[15] E. X. Yang, Y. M. Jiang, G. C. Hua, and F. C. Lee, "Isolated boost circuit for power factor correction," in Proc. IEEE APEC, pp. 196-203, 1993.

[16] L. Z. Zhu, K. R. Wang, F. C. Lee, and J. S. Lai, "New start-up schemes for isolated full-bridge boost converters," IEEE Trans. Power Electron., Vol. 18, No. 4, pp. 946-951, Jul. 2003.

[17] Y. Panov, J. G. Cho, and F. C. Lee, "Zero voltage switching three-phase single-stage power factor correction converter," IET Electr. Power Appl., Vol. 144, No. 5, pp. 343-348, Sep. 1997.

[18] V. Yakushev, V. Meleshin, and S. Fraidlin, "Full-bridge isolated current fed converter with active clamp" in Proc. IEEE APEC, pp. 560-566, 1999.

[19] E. S. Park, S. J. Choi, J. M. Lee, and B. H. Cho, "A soft-switching active-clamp scheme for isolated full-bridge boost converter" in Proc. IEEE APEC, pp. 1067-1070, 2004.

[20] D. Q. Wang, H. Q. Ben, and T. Meng, "A novel three-phase power factor correction converter based on active clamp technique," in Proc. IEEE ICEMS, pp. 1896-1901, 2008.

[21] D. Q. Wang, H. Q. Ben, T. Meng, and Z. B. Lu, "Sing-stage full-bridge PFC technique based on clamp circuit", Electric Power Automation Equipment (China), Vol. 30, No. 5, pp. 53-56, May 2010.

[22] T. Meng, H. Q. Ben, and D. Q. Wang, "The passive snubber circuit suitable for a three-phase sing-stage full-bridge PFC converter," Transactions of China Electrotechnical Society, Vol. 25, No. 2, pp. 94-100, Feb. 2010.

[23] T. Meng, H. Q. Ben, D. Q. Wang, and J. M. Zhang, "Research on a novel three-phase single-stage boost DCM PFC topology and the dead zone of its input current," in Proc. IEEE APEC, pp. 1862-1866, 2009.

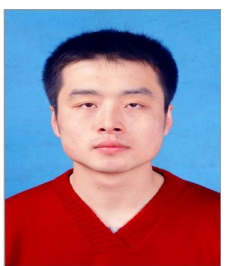

Tao Meng was born in Liaoning Province, China, in 1980. He received his B.S., M.S. and Ph.D. in Electrical Engineering from the Harbin Institute of Technology, Harbin, China, in 2003, 2005 and 2010, respectively. Since 2007, he has been an Engineer with the School of Electrical Engineering and Automation, Harbin Institute of Technology. His research interests include active power factor correction techniques and their application. 


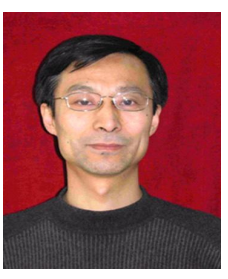

Hongqi Ben was born in Heilongjiang Province, China, in 1965. He received his B.S. in Electrical Engineering from the Shenyang University of Technology, Shenyang, China, in 1988, his M.S. in Electrical Engineering from the Harbin Institute of Technology, Harbin, China, in 1991 and his Ph.D. in Mechatronics Engineering from the Harbin Institute of Technology, Harbin, China, in 1999. Since 2004, he has been a Professor with the School of Electrical Engineering and Automation, Harbin Institute of Technology. His research interests include high frequency power conversion techniques and active power factor correction techniques.

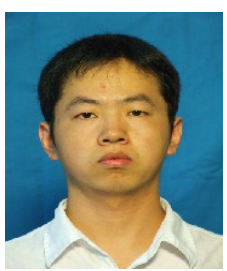

Daqing Wang was born in Jilin Province, China, in 1984. He received his B.S. in Electrical Engineering from the Dalian University of Technology, Dalian, China, in 2006, and his M.S. in Electrical Engineering from the Harbin Institute of Technology, Harbin, China, in 2008, where he is currently working toward his $\mathrm{Ph} . \mathrm{D}$. His research interests include active power factor correction techniques and their application.

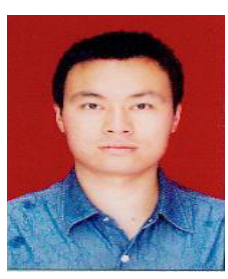

Jianfeng Song was born in Shanxi Province, China, in 1982. He received his B.S. in Launch Engineering from the Second Artillery Engineering College, Xi'an, China, in 2005, and he is currently working toward his M.S. in Electrical Engineering at the Harbin Institute of Technology, Harbin, China. His research interests include AC-DC converters and soft-switching power converters. 